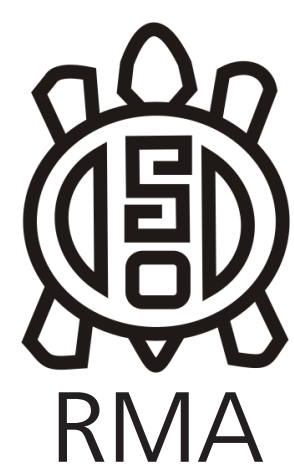

Dossier

\title{
Lengua y territorio: variación histórica y dialectal del wichí/weenhayek (familia mataguaya)
}

\author{
Language and territory: historical and dialectal variation in Wichil \\ Weenhayek (Mataguayan)
}

Verónica Nercesian*

*CONICET, Instituto de Filología y Literaturas Hispánicas "Dr. A. Alonso", Facultad de Filosofía y Letras, Universidad de Buenos Aires, Argentina.

E-mail: vnercesian@conicet.gov.ar

Wichí: La palabra

\begin{abstract}
Resumen
Este trabajo presenta los resultados de una investigación en curso sobre la variación dialectal en wichí/weenhayek (familia mataguaya). Se analiza la distribución geográfica de al menos cinco rasgos que definen dos complejos dialectales con mayor tiempo de divergencia, el pilcomayeño y el bermejeño, y zonas de transición en la cadena dialectal. Esta agrupación se solapa con otro nivel de variación que habría de ser más reciente y que, a partir de las isoglosas de otras cinco variables, distingue al bermejeño abajeño del arribeño y del pilcomayeño. Este último también presentaría una subdivisión en abajeños y arribeños. El presente estudio se combina con la lingüística histórica para comprender la variación en espacio y tiempo. Se presentan hipótesis evolutivas que explicarían el estado actual de la variación dialectal. Estos resultados constituyen un aporte novedoso al conocimiento de la variación del wichí/weenhayek y la historia del pueblo que la habla.
\end{abstract}

Palabras clave: Gran Chaco; Wichi/weenhayek; Variación dialectal; Lingüística histórica.

\begin{abstract}
This paper presents the results of ongoing research on dialectal variation in Wichi/Weenhayek (Mataguayan language family). We analyze the geographical diffusion of five features that define two dialectal groups with the longest time of divergence, the Pilcomayeño and the Bermejeño, and transition zones in the dialectal chain. This grouping overlaps with another level of variation that would have to be more recent. From the isoglosses of other five linguistic variables, we identify the Bermejeño Abajeño variety separately from the Bermejeño Arribeño and the Pilcomayeño. This last group would also present a subdivision into Arribeño and Abajeño. This study combines dialectology and historical linguistics to understand the variation in space and time. We present evolutionary hypotheses that would explain the current stage of variation. The results presented in this paper constitute a novel contribution to the knowledge of variation in Wichi/Weenhayek and the history of the people.
\end{abstract}

Keywords: Gan Chaco; Wichi/weenhayek; Dialectal variation; Historical linguistics.

\section{Introducción}

La lengua wichí/weenhayek ${ }^{1}$ es hablada en un amplio territorio por aproximadamente 32.000 personas en el área del Gran Chaco (29.066 hablantes en Argentina, según el INDEC-ECPI (2004-2005), y 4.115, según la ORCAWETA (2011 p. 18)), aunque se especula que el número sea aún mayor. Debido en buena medida a esa extensión territorial, la lengua presenta variaciones dialectales o diatópicas (es decir, según la zona geográfica), de las cuales se tiene registro por lo menos desde el siglo XIX. Este ha sido un tema de interés para lingüistas y antropólogos. Empero, existen pocos

\footnotetext{
1 En este trabajo empleamos los términos wichí/weenhayek para referir al pueblo y su lengua respetando las autodenominaciones en uso en Argentina y el Estado Plurinacional de Bolivia.
}

antecedentes, los cuales mencionan algunos rasgos de variación a partir de la comparación de algunas fuentes, con datos reducidos y sin una metodología clara. Actualmente, contamos con una documentación mucho más amplia y representativa de la lengua en diversas zonas, con fuentes antiguas y con un conocimiento de la lengua mucho más profundo, situación que nos permite realizar un estudio lingüístico más acabado de la variación dialectal, que a su vez nos permite comprender los niveles o capas de esa variación.

Este trabajo presenta algunos hallazgos de la investigación lingüística sobre la variación histórica y geográfica del wichí/weenhayek en curso (cf. Nercesian, 2013, 2019a, 2019b, en prensa). Partimos del presupuesto de que la variación y la historia de la lengua son inseparables de 
la historia del pueblo. En este sentido, los fenómenos lingüísticos entran en relación con los sociales, y desde ese lugar este trabajo también contribuye a los estudios socio-históricos del pueblo. Este estudio sistémico sobre la variación no solo aporta el hallazgo de rasgos de variación diatópica no identificados hasta el momento, sino además la distribución geográfica de las variantes y el delineamiento de isoglosas (mapeo de la distribución geográfica de las formas lingüísticas). Esto permite configurar los complejos dialectales en función de parámetros lingüísticos representativos. Para este estudio se realizaron diversos trabajos de campo y se consultaron fuentes primarias y secundarias. En el anexo, se especifica la procedencia de los datos de cada fuente y de los trabajos de campo realizados.

En la sección 2, exploramos la relación del wichí/ weenhayek con el resto de las lenguas de la familia lingüística; en la sección 3, se analizan los rasgos de variación dialectal y al menos dos niveles de esa variación. En la sección 4, se presentan algunas hipótesis evolutivas que explican el desarrollo de las variantes actuales y se las relaciona con aspectos históricos del pueblo. Finalmente, en 5, se presentan los comentarios finales.

\section{Algunos rasgos lingüísticos de la familia mataguaya}

El wichí/weenhayek pertenece a la familia lingüística mataguaya (también denominada mataco-mataguayo o mataco), junto con el chorote, el maká y el nivaĉle. Una familia lingüística es un grupo de lenguas que tienen un origen en común. Basta aproximadamente un siglo de divergencia para que emerjan variedades en una lengua y aproximadamente mil años, para que emerjan dos o más lenguas cuando antes existía una sola (Bynon, 1977). Dado su origen común, esas dos o más lenguas están emparentadas y forman una familia lingüística. Si bien todavía no sabemos en profundidad la historia de la familia mataguaya, se pudo avanzar en la formulación de algunas hipótesis evolutivas. A partir de un estudio léxico-estadístico, basado en la comparación de términos entre las lenguas, Antonio Tovar (1964, 1981) concluyó que el chorote y el wichí/weenhayek son las lenguas que están más estrechamente emparentadas. Siguiendo lo que se deduce de estas conclusiones, Alain Fabre (2005: 3) postuló la existencia de dos ramas principales: (I) wichí, chorote, (II) nivaĉle, maká. No obstante, este lingüista plantea la necesidad de reevaluar la ubicación del chorote puesto que, si se consideran ciertos rasgos gramaticales, esta lengua está más próxima al maká y al nivaĉle, lo que implicaría que el wichí/weenhayek se habría separado del resto más tempranamente.

En el wichí/weenhayek contemporáneo se encuentran rasgos fonológicos, morfológicos, sintácticos y léxicos compartidos con las lenguas de la familia. Entre los fonológicos, el chorote, el nivaĉle y el wichí/weenhayek poseen seis vocales: /i, e, a, a, o, u/. En el caso del wichí/weenhayek, como veremos en 3.1, la oposición fonológica /a/ y /a/ (ortográficamente, $<a>$ y $<\ddot{a}>$ respectivamente) se neutralizó en el grupo dialectal bermejeño, quedando cinco vocales /i, e, a, o, u/. En cuanto a las consonantes, por ejemplo, son fonemas característicos en las cuatro lenguas de la familia la lateral fricativa sorda, /1/ (representada ortográficamente como $<x l>$ en chorote, como $<l>$ en maká, y como $</ h>$ en nivaĉle y en wichí/weenhayek), la glotal oclusiva /?/ $<^{\prime}>$ y la serie de consonantes eyectivas sordas $\left[p^{\prime}, t^{\prime}, k^{\prime}\right.$, $\left.q^{\prime}\right]<p^{\prime}, t^{\prime}, k^{\prime}, q^{\prime}>$.

Los rasgos morfológicos compartidos son abundantes. Por ejemplo, en las cuatro lenguas, el derivativo aumentativo es un cognado (términos formalmente emparentados, es decir, que tienen un mismo origen etimológico) como se ilustra en (1).

(1) Wichí/weenhayek. alhetaj alhutaj 'yacaré' < alhe alhu 'iguana'

Chorote. ajlyutje 'yacaré' < ajlyu' 'iguana'

(Carol, 2014 p. 388)

Nivaĉle. ekletax 'papagayo' < ekle 'loro'

(Stell, 1987 p. 205)

Maká. ehe'tax 'papagayo' < ehe' 'loro'

(Tacconi, 2015 p. 103)

Asimismo, la construcción posesiva es un rasgo de la familia. Estas lenguas clasifican a los sustantivos en alienables (sin poseedor inherente) e inalienables (con poseedor inherente, es decir, se interpreta que por definición lo denotado le pertenece a alguien). Este último grupo de sustantivos indica de manera obligatoria la persona poseedora cada vez que se nombran. Suelen referir a partes del cuerpo, relaciones de parentesco (como 'madre', 'padre', 'hermano') y algunos objetos personales que se usan sobre el cuerpo (como 'pantalón', 'bastón', 'collar'). Los sustantivos alienables, en cambio, suelen referir a fenómenos de la naturaleza, objetos en general, personas y animales, y pueden nombrarse sin expresar un poseedor. Cuando están poseídos, añaden un clasificador posesivo entre el morfema que indica la persona poseedora y el sustantivo. Además de compartir esta estructura morfológica, el clasificador es un cognado en las cuatro lenguas ( $k / q+$ vocal); véase (2).

$$
\begin{aligned}
& \text { Wichí/weenhayek. n'-ka-hele o-ka-hilu } \\
& \text { mi-CL-yica mi-CL-yica } \\
& \text { 'mi yica' 'mi yica' }
\end{aligned}
$$

Chorote. ji-ka-wonta

su-CL-sombrero

'su sobrero'

(Carol, 2014 p. 40)

Nivaĉle. kaci-ka-tajex 


\author{
nuestro, a-CL-shamán \\ 'nuestro shamán' \\ (Stell, 1987 p. 188) \\ Maká. ye-qe-nenek \\ mi-CL-cuchara \\ 'mi cuchara' \\ (Gerzenstein, 1994 p. 149)
}

Otra característica morfosintáctica que el wichí/ weenhayek comparte con las otras lenguas de la familia es la marcación del objeto de la oración (el participante que recibe la acción del verbo) como prefijo (es decir, antes de la raíz verbal) en la estructura morfológica; véase $(3)^{2}$. Como veremos más adelante, en wichí/ weenhayek en particular, el pronombre de segunda persona es un prefijo y el de primera es un sufijo (se añade después del verbo), pero en el grupo bermejeño en particular, el objeto es siempre un sufijo sin importar si es de primera o segunda persona. En nivaĉle, el prefijo de objeto está amalgamado con el sujeto.

\section{(3) Wichí/weenhayek pilcomayeño.o-a-ichufwan yo-te-enseñar 'Yo te enseño.'}

\begin{tabular}{|c|c|}
\hline Chorote. & $\begin{array}{l}\text { si-'ye'en } \\
\text { me-mirar } \\
\text { 'Me mira/mirás.' } \\
\text { (Carol, } 2014 \text { p. 124) }\end{array}$ \\
\hline Nivaĉle. & $\begin{array}{l}\text { tsi-'van } \\
\text { el, ella/me-ver } \\
\text { 'Él me ve.' } \\
\text { (Fabre, } 2014 \text { p. 139) }\end{array}$ \\
\hline Maká. & $\begin{array}{l}\text { te-tsi-fen } \\
\text { vos-me-ayudar } \\
\text { 'Vos me ayudás.' } \\
\text { (Gerzenstein, } 1994 \text { p. 100) }\end{array}$ \\
\hline
\end{tabular}

Además, en todas las lenguas esos verbos pueden formarse con un sufijo que indica dirección o locación de la acción (algunos con extensión semántica a benefactivo o asociativo), en cuyo caso, el objeto sintáctico se añade entre el verbo y el sufijo, como en (4). En el caso del wichí/weenhayek, esta estructura morfológica se da

\footnotetext{
2 Si bien el chorote, el maká y el nivaĉle presentan una estructura morfológica verbal con el objeto prefijante, como se ilustra en los ejemplos en (3), también hay que destacar que esos sistemas de marcación de persona presentan particularidades no presentes en wichí/ weenhayek. Entre otras, que estas lenguas poseen distintas series de paradigmas pronominales según la distinción semántica del participante activo/inactivo, y que la marcación de los participantes está regida por una jerarquía de persona. Además, algunos verbos emplean la forma sufijante de objeto en lugar de la prefijante, y en algunos casos sujeto y objeto pueden estar amalgamados en un mismo prefijo. No obstante, desde el punto de vista de la estructura morfológica verbal, nos interesa resaltar la posibilidad de marcación del objeto (o participante inactivo) como prefijo como rasgo compartido en la familia.
}

igual en todas las variedades. En chorote, muchos sufijos están fusionados con los pronombres de objeto.

(4)

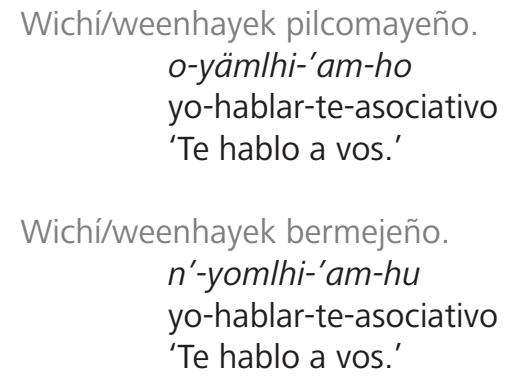

En el plano del léxico, hay cognados entre las lenguas de la familia; presentamos algunos en la Tabla $1 .{ }^{3} \mathrm{La}$ semejanza formal entre los términos no siempre se ve entre las cuatro lenguas: en algunos casos las palabras de dos lenguas se parecen más entre sí, con respecto a las otras dos, o una se diferencia más con respecto a las otras tres, y así sucesivamente. Esto se debe a que los cambios lingüísticos no se dan de la misma manera en cada caso y por lo tanto los resultados son diferentes.

Comparativamente, el wichí/weenhayek contemporáneo parece ser el que más se ha distanciado del tronco mataguayo, e internamente a esta lengua, como veremos, la más alejada es la variedad bermejeña abajeña. El conocimiento de los rasgos que el wichí/ weenhayek comparte con el resto de la familia es necesario para el estudio de historia y para la comprensión de los fenómenos que encontramos en sincronía en esta lengua.

La lingüística histórica de la familia mataguaya, también nos habla de la historia del pueblo en la región chaqueña. Según Susnik (1972 p. 24), los grupos mataguayos debieron haber ingresado al Gran Chaco de norte a sudeste, posiblemente presionados por el grupo amazónico arawak. Sobre esta hipótesis y los

\footnotetext{
${ }^{3}$ Los términos del chorote y el maká fueron tomados de Gerzenstein (2015a y b) y los del nivaĉle, de Seelwische y Stell (2015). Las transcripciones fonéticas se adaptaron al sistema ortográfico.
} 
Tabla 1. Cognados léxicos en las lenguas mataguayas.

Table 1. Lexical cognates in the Mataguayan languages.

\begin{tabular}{|c|c|c|c|c|}
\hline & Wichi/weenhayek & Chorote & Nivaĉle & Maká \\
\hline 'agua' & inot $\sim$ inät & i'niat & inôôt & iweli \\
\hline 'fuego' & itoj itäj & jwat & itoj & fet \\
\hline 'monte' & tayhi tañhi & 'Ia'an & yita' & tene' \\
\hline ‘luna' & wel'a & $w e^{\prime} / a$ & jive'cla & juwel \\
\hline 'sol' & fwala $\sim$ xwala & kilie' $^{\prime}$ & jumcuclaai & junu' \\
\hline 'cielo' & pele pule & poli & vốs & was \\
\hline 'tierra' & hunhat honhat & ajnat & natu & sehe' \\
\hline 'mi hijo' & $n^{\prime}$-Ihos $\sim 0$-Ihäs & $y$-as & $y$-ấs & $y$-as \\
\hline 'mi esposo, a' & $n^{\prime}-c h^{\prime} e f w a \sim 0-c h^{\prime} u f w a$ & ikilfw$^{w} a^{\prime} \sim$ inilfw ${ }^{w} a^{\prime}$ & $y i-c h^{\prime} a k f a$ & $y$-iwheye' \\
\hline 'mi cabeza' & $n^{\prime}$-lhetek $\sim 0$-lhetek & i-iyitik & yi-shatech & $y i-j i t a^{\prime}$ \\
\hline
\end{tabular}

antecedentes de Métraux (1946) entre otros, Vidal y Braunstein (2020) sugieren que, de ser cierto, eso debió haber ocurrido muy lentamente. Observamos que si la dirección del desplazamiento geográfico del grupo mataguayo fue de norte a sudeste, el grupo wichíl weenhayek bermejeño abajeño es el más alejado del núcleo mataguayo, aspecto que se replica en los rasgos lingüísticos de esta variedad (cf. sección 3.2). Además, basados en la similitud del decorado en la cerámica, Vidal y Braunstein (2020) afirman que, antes de entrar en el área chaqueña, los mataguayos debieron haber tenido algún tipo de intercambio con los arawak agricultores que vivían al pie de la montaña. Entre los rasgos lingüísticos, algunas lenguas arawak del norte presentan una serie de fonemas oclusivos aspirados: $/ \mathrm{p}^{\mathrm{h}}, \mathrm{t}^{\mathrm{h}}, \mathrm{k}^{\mathrm{h}}$ / (cf. Aikhenvald 1999 p. 76), como el wichí/weenhayek. Sin concluir que el desarrollo de las aspiradas estuvo motivado por el contacto, destacamos como dato relevante para el análisis que, en algún momento, al menos algunas variedades wichí/weenhayek estuvieron en contacto con lenguas que también tenían series aspiradas.

El estudio de la familia mataguaya es relativamente incipiente, y se han sugerido algunas propuestas para la reconstrucción del proto-mataguayo (esto es, una hipótesis de lo que pudo haber sido la lengua ancestral que dio origen a las cuatro de la familia). La primera propuesta fue la de Najlis (1984), quien reconstruyó el proto-sistema fonológico que sirvió de base para las siguientes reconstrucciones sugeridas por Viegas Barros (1993, 2002, 2013). Según este autor, el inventario de consonantes habría sido el siguiente: ${ }^{*} p{ }^{*} t{ }^{*} t s{ }^{*} k$ * $q$ *?, ${ }^{*} p^{\prime}{ }^{*} \mathrm{t}^{\prime}{ }^{*} \mathrm{ts}{ }^{\prime}{ }^{*} \mathrm{k}^{\prime}{ }^{*} \mathrm{q},{ }^{*} \mathrm{w}{ }^{*} \mathrm{k}{ }^{*},{ }^{*} \mathrm{k}{ }^{*} \mathrm{~s}{ }^{*} \mathrm{~h}{ }^{*} \mathrm{~h}{ }^{\mathrm{w}},{ }^{*} \mathrm{~m}{ }^{*} \mathrm{n}, \mathrm{y}$ el de vocales: ${ }^{*}{ }^{*} e{ }^{*} a{ }^{*}{ }^{*}{ }^{*} \mathrm{o}{ }^{*} u$. Sobre estas hipótesis, Gutiérrez y Nercesian (en prensa) aportaron pruebas que sustentan la reconstrucción de un sonido glotal oclusivo $/ 2 /$, ausente en las primeras propuestas de Viegas Barros (1993, 2002).

Por último, las lenguas mataguayas comparten algunos rasgos fonológicos y gramaticales con lenguas de la familia guaycurú (moqoit, pilagá y qom), por ejemplo, los segmentos posvelares, la palatalización, la coincidencia formal entre el pronombre ligado de persona poseedora y de sujeto, la distinción alienable/ inalienable en los sustantivos, el sistema de deícticos demostrativos, entre otros. Estas semejanzas han sido interpretadas de dos maneras. Por un lado, se sugiere la hipótesis de una relación genética entre la familia mataguaya y la guaycurú (cf. Greenberg, 1987, Viegas Barros, 1993, 2013, Campbell, 2000), y, por el otro, la hipótesis de que existe un área lingüística en donde se ha dado el contacto lingüístico entre lenguas de al menos siete familias distintas (guaycurú, mataguaya, enlhetenenlhet o lengua-maskoy, zamuco, arawak, lule-vilela y tupí-guaraní) y dos lenguas aisladas (besïro o chiquitano y guató) (cf. Lafone Quevedo, 1895, 1912, Tovar, 1951, Comrie et al., 2010, Golluscio y Vidal, 2009-2010, González 2015, Messineo, Carol y Klein, 2015, entre otros). Precisamente, el argumento para sostener que los rasgos compartidos se deben al contacto, es que muchos de ellos también están presentes en lenguas de otras familias lingüísticas de la región chaqueña. Los estudios en ambas direcciones aún se encuentran en la búsqueda de pruebas suficientes que sustenten esas hipótesis.

\section{La variación dialectal del wichí/weenhayek}

Desde la dialectología, se afirma que las diferencias entre variedades lingüísticas son acumulativas, es decir, se harán cada vez mayores a medida que nos alejamos de un punto de partida. Por eso, cuanto más grande sea la separación geográfica de los grupos, mayor será la dificultad de comprensión, pero estarán conectados por una cadena de inteligibilidad mutua. Esta situación es la que se denomina 'continuum geolectal' o 'continuum dialectal' (Chambers y Trudgill, 1994, Trudgill, 2011). Y dado que la variación es gradual, las variedades lingüísticas no son unidades discretas. Por eso veremos en el análisis de la variación dialectal del wichí/weenhayek que las agrupaciones propuestas aquí se superponen y la distribución de las formas en uso en 
el territorio presentan zonas geográficas 'de transición' (Chambers y Trudgill, 1994).

La variación diatópica del wichí/weenhayek ha sido documentada al menos desde la segunda mitad del siglo XIX por distintos lingüistas. Samuel Lafone Quevedo (1895, 1896a, 1896b, 1897), propuso la existencia de cuatro variedades: 1 Nocten -según los apuntes del P. Inocencio Massei-, 2 Vejoz -según el MS conservado por d'Orbigny, recientemente adjudicado al franciscano Primo Ayala y datado hacia fines del XVIII (cf. Combès y Montani, en este dossier)-, 3 Mataco -según las publicaciones del P. Remedi- y 4 Mataco -según los apuntes del Ingeniero Pelleschi-. Avanzado el siglo $X X$, Tovar (1961; 1964), distinguió tres dialectos: 1 Vejoz, hablado en la ciudad de Embarcación (Salta), 2 Guisnay, en el este de Salta (Mosconi, Tartagal, Misión La Paz) y oeste de Formosa (El Potrillo), y 3 Noctén en Villamontes, en el Estado Plurinacional de Bolivia. En 1968, Elena Najlis hizo referencia a las discrepancias que ya existían para la época con respecto a las variedades dialectales y propuso una división en cinco: 1 los vejoces, en el límite oeste, 2 los noctenes, en el norte, extremo oeste, 3 los guisnais, en el norte, parte central y este (el límite entre noctenes y guisnais cambia notablemente de una fuente a otra), 4 los montaraces, en la zona entre los dos ríos, y 5 los matacos a secas en todo el sur de la región. Gerzenstein (1992) y Golluscio (1993a, 1993b) sumaron la "variedad oriental" o "dialecto del Teuco", respectivamente. Según Golluscio (1993a), el dialecto del Teuco debería ser una cuarta variedad no considerada en la clasificación de Tovar. Por su parte, Gerzenstein (2003) distinguió tres grupos: 1 el wichí boliviano (weenhayek), según Claesson (1994), 2 el wichí salteño, según Viñas Urquiza (1974), y 3 el wichí oriental, según sus propios datos recogidos en comunidades de Las Lomitas (Formosa), el cual se subdivide en: arribeños y abajeños según el curso del río Bermejo. Finalmente, desde una perspectiva antropológica, Messineo y Braunstein (1990) sugirieron la hipótesis de que la variación lingüística estaría relacionada con la distribución de las tribus (conjuntos de bandas aliadas) históricamente asentadas en la región. Habría, entonces, tantos sociolectos (variantes según factores sociales) cuantas tribus existen en el pueblo. Sin embargo, en tanto la variación sociolectal y la dialectal responden a factores extralingüísticos diferentes, la hipótesis de Messineo y Braunstein (1990), todavía no constatada, no se contrapone con las anteriores.

Las diversas propuestas de división en variedades dialectales, así como la documentación de la lengua, constituyen antecedentes esenciales para este estudio. Por primera vez, se analizan integralmente rasgos de distintos niveles lingüísticos, a partir de datos propios y de una amplia variedad de fuentes secundarias, y se delinean isoglosas que sustentan la división de los grupos dialectales. Este estudio de la variación, además, se combina con la lingüística histórica para comprender el recorrido evolutivo de esa variación. Por el momento, hemos logrado identificar un conjunto de rasgos gramaticales y fonológicos que sustentan la división en dos complejos dialectales, pilcomayeño y bermejeño, aparentemente más antigua, y una subdivisión al interior de estos en arribeños y abajeños que se habría dado en períodos distintos. Las isoglosas delineadas muestran que, como se dijo, estas divisiones no son discretas. Es un conjunto de rasgos compartido el que permite identificar los grupos que, desde ya, se asumen heterogéneos. La variación en una lengua puede llegar al punto de la variación facultativa, es decir, de las variantes usadas por cada hablante. Cuando hacemos un estudio de variaciones dialectales se identifican aquellos rasgos que son compartidos por conjuntos de hablantes en una zona geográfica, de allí la importancia de las isoglosas. Estas permiten establecer las hipótesis respecto de los grupos dialectales según mayor o menor coincidencia de cantidad de isoglosas (Bynon, 1977, Milroy y Gordon, 2003).

Cuando hay variación dialectal en una lengua, quiere decir que esa experimentó cambios lingüísticos que se dieron de manera despareja en el territorio de habla, en distintas direcciones, o en distintos momentos. Es decir que la variación de una lengua supone el cambio lingüístico en el tiempo. Teniendo en cuenta la velocidad de esos cambios, el estudio de la variación que realizamos se focalizó, primeramente, en rasgos morfológicos. Según Trudgill (2011), esos ocurren con mayor lentitud que los léxicos y fonológicos. Wichmann y Holman (2009) sostienen que los rasgos estructurales básicos tienden a ser estables, mientras que rasgos pragmáticamente sensibles, como fenómenos de cortesía y evidenciales, ${ }^{4}$ tienden a ser más inestables. El análisis de la variación de rasgos más estables nos permitió identificar los complejos dialectales con mayor tiempo de divergencia, y luego estudiar la variación dentro de esos complejos.

\subsection{Los complejos dialectales pilcomayeño y bermejeño}

El hallazgo de un primer conjunto de rasgos estructurales (fonológicos y morfológicos) permitió el reconocimiento de dos complejos dialectales que habrían de tener mayor tiempo de divergencia: el pilcomayeño y el bermejeño. Esta denominación proviene de la distribución territorial tradicional de los grupos en torno a los ríos Pilcomayo y Bermejo, respectivamente. No obstante, la difusión geográfica de las formas lingüísticas no es completamente homologable a la distribución de los grupos en términos sociales. Los grupos de la zona de Embarcación, Salta, quedaron incluidos en lo que denominamos grupo pilcomayeño, a pesar de que

\footnotetext{
${ }^{4}$ Los evidenciales son partículas (libres o ligadas) que indican la fuente de conocimiento del contenido del enunciado, por ejemplo, pueden indicar que el hablante conoce lo que enuncia porque lo vio o porque se lo contaron.
} 


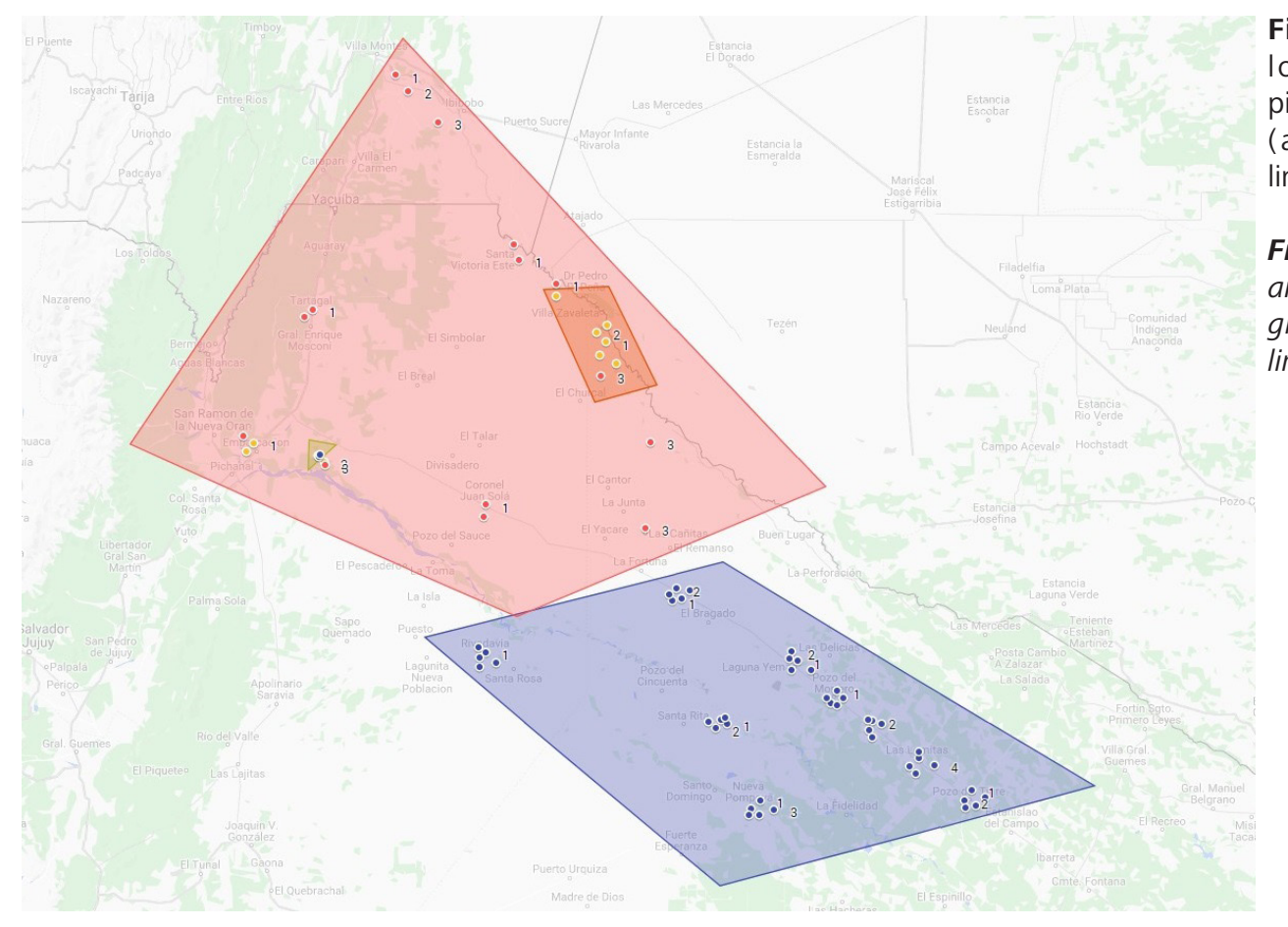

Figura 1. Configuración de los complejos dialectales pilcomayeño (rojo) y bermejeño (azul) según isoglosas lingüísticas.

Figure 1. Pilcomayeño (red) and Bermejeño (blue) dialectal groups division according to linguistic isoglosses.

actualmente las comunidades se encuentren en la ribera río arriba del Bermejo, puesto que, según las variables analizadas hasta el momento, los grupos de esa zona comparten las variantes fonológicas y morfológicas con el resto del pilcomayeño. En la misma zona, sin embargo, hay comunidades, como El Carboncito que, como veremos, forma parte del complejo lingüístico bermejeño. Para comprender la difusión de las variantes, la localización territorial de estos dos grupos en términos lingüísticos se configura a partir de las isoglosas (véase Figura 1). Las variables seleccionadas son: (1) presencia/ ausencia de una serie de consonantes aspiradas con valor fonémico; (2) cantidad de vocales en el inventario fonológico; (3) pronombre libre y prefijo pronominal sujeto de primera persona; (4) pronombre libre y prefijo pronominal sujeto de primera persona plural persona indefinida; y (5) objeto pronominal prefijante/sufijante.

En el mapa de la Figura 1 puede observarse que hay zonas de transición que a su vez podrían estar configurando el grupo pilcomayeño abajeño. Además, puede observarse la presencia de variantes bermejeñas en "la zona pilcomayeña". Se trata de la comunidad antes mencionada, El Carboncito (Salta), formada en 1977 con el traslado de unas 100 familias de Los Blancos, San Patricios (Salta) y Pozo Yacaré (Formosa) por parte de la Iglesia Anglicana (Serrudo, 2006, Montani y Juárez, 2015). La creación de esta comunidad se realizó en el marco del proyecto San Miguel que contempló la adquisición de 1600 ha correspondientes a una facción de los predios de la entonces denominada "Finca Carboncito", para el desarrollo de actividades principalmente agrícolas, pero también de carpintería y fabricación de carbón, y con ello la oferta laboral a los indígenas. El objetivo principal era la creación de comunidades con estabilidad e independencia económica (Wallis, 1985, en Serrudo, 2006).

En suma, la zona geográfica de Embarcación y sus alrededores en la provincia de Salta merece un análisis particular y más profundo. Por diversos motivos, esta parece haber sido históricamente una zona de confluencia de grupos distintos que presentaban variaciones lingüísticas, incluso desde un siglo antes. Por ejemplo, en un relato del Padre Giannecchini citado por Lafone Quevedo $(1895,1896)$ se destaca que hacia fines del siglo XVIII el colegio Misionero Franciscano fundó en Centa (Orán, Argentina) una misión en la que convivieron grupos "mataguayos" y "vejoces". Los llamados mataguayos (grupo del pueblo wichí/weenhayek según Lafone Quevedo) ocupaban la margen derecha del río Bermejo, y los vejoces, la izquierda llegando hasta Itiyuru de Caiza (sus descendientes, esparcidos por el Itiyuru, eran conocidos por entonces como "matacos del río Seco"). Para mediados de siglo XIX no quedaban más que los cimientos.

Nos adentraremos ahora en el análisis del conjunto de rasgos que definen los complejos dialectales. La variable 1 , que consiste en el estatus fonológico de la serie de oclusivas aspiradas, es un hallazgo novedoso de esta investigación. Observamos que el grupo pilcomayeño posee consonantes $\left[\mathrm{p}^{\mathrm{h}}\right]<p h>,\left[\mathrm{t}^{\mathrm{h}}\right]<t h>,\left[\mathrm{k}^{\mathrm{h}}\right]<k h>\sim\left[\mathrm{q}^{\mathrm{h}}\right]$ $<q h>$ como alófonos de los fonemas oclusivos plenos /p/ $<p>$, /t/ $<t>$ y /k/ $<k>\sim / q /<q>$ (cf. Avram, 2008, Tovar, 1958, 1981, Fernández Garay y Spinelli, 2009, Viñas Urquiza, 1974). Esto quiere decir que en esta variedad o complejo dialectal la consonante /p/, por ejemplo, puede pronunciarse como $\left[\mathrm{p}^{\mathrm{h}}\right]$ en determinados contextos sin producir un cambio en el significado de la palabra que 
contiene ese sonido. En el extremo norte del continuum wichí/wenhayek, en la zona de Villamontes y la margen derecha del río Pilcomayo hacia el sur (Tarija, Bolivia), estos sonidos fueron analizados como grupos consonánticos (Claesson, 1994, 2017). En el grupo bermejeño, en cambio, $/ \mathrm{p}^{\mathrm{h}} /$, $/ \mathrm{t}^{\mathrm{h}} / \mathrm{y} / \mathrm{k}^{\mathrm{h}} / \sim / \mathrm{q}^{\mathrm{h}} /$ son fonemas distintos a $/ \mathrm{p} /$, /t/ y /q/, por lo tanto, la pronunciación aspirada cambia el significado. En Rivadavia, Banda Sur, que es la zona alta del río Bermejo estas consonantes aspiradas fueron registradas como alófonos de las plenas, como en el pilcomayeño. Pero según Terraza (2009a y b), su estatus alofónico se debe al proceso de retracción de la lengua en esa zona. En este grupo, la alternancia plena/aspirada depende de una variación etaria, hasta donde pudo observar: "los más jóvenes no pronuncian la aspiración en el interior de los morfemas. En los casos en que la aspiración es el resultado de la unión de dos morfemas, su pronunciación varía de un hablante a otro" (Terraza, 2009a p. 29). La autora concluye que esta variación se debe a la inestabilidad de esta zona del sistema fonológico de la lengua y que "se trata de realizaciones inestables que habrían sido quizás más frecuentes en el pasado pero que tienden a desaparecer" (Terraza, 2009a p. 29ss). Considerando esta afirmación, el grupo de esta zona geográfica forma parte del complejo dialectal bermejeño, caracterizado por la presencia de consonantes aspiradas en el inventario fonológico.

Según la última reconstrucción fonológica del proto-mataguayo de Viegas Barros (2013), la serie aspirada de consonantes no era parte del inventario; consecuentemente, esta serie habría evolucionado en el bermejeño pero no el pilcomayeño. Esta hipótesis se apoya, además, en el hecho de que en el bermejeño, que presenta la serie fonológica, esta se configura a partir de pares (cuasi) mínimos de contraste entre la plena y la aspirada, a diferencia del contraste entre la plena y la eyectiva. Compárense los términos taypho [tajpho] 'sentate' / t'aypho [t'ajpho] 'sube', y tefw [tefw] 'come algo' / t'ek [t'ek] 'come' / thej [thex] 'choca con algo', o atak [?ataq] 'mosca' / atha [?atha] 'es difícil' (cf. Nercesian, 2014). Se dice que los pares contrastivos son cuasi mínimos porque el contexto fónico en el que ocurren no es completamente idéntico; lo que tienen en común son, principalmente, las vocales que preceden y que siguen a la consonante en comparación. Quiere decir que desde el extremo norte de la cadena dialectal wichí/weenhayek hacia el extremo sudeste, se observa una progresión en la evolución de la serie de consonantes aspiradas que va desde grupos consonánticos y aspiradas con estatus alofónico, en el grupo pilcomayeño, hasta una serie completa con estatus fonémico, relativamente estable, en el grupo bermejeño. Un recorrido evolutivo similar experimentó la serie de nasales y semiconsonantes aspiradas [n] $<n h>,\left[\mathrm{m}_{\mathrm{o}}\right]<m h>,\left[{ }^{\circ}\right]<y h>$, [w] $<w h>$.

El inventario fonológico de vocales también presenta diferencias entre los dos complejos dialectales, como observaron Najlis (1968) y Messineo y Braunstein (1990). La variable 2 consiste, en particular, en el contraste entre $/ a /<a>y / a /<\ddot{a}>$. Mientras que ese contraste fonológico está presente en el pilcomayeño, en el bermejeño, se ha neutralizado, quedando la [a] como variante de /a/ después de consonantes posteriores como $[q]<k>$ y $[\chi]$ $<j>\sim<j h>$. Según la reconstrucción del proto-mataguayo, la vocal /a/ ya existía como proto-fonema, por eso concluimos que la evolución del inventario vocálico se orientó hacia la neutralización del contraste. De hecho, en zonas del pilcomayeño, como Misión La Paz (Salta), [a] es una variante de /a/ (cf. Avram, 2008), y en San Andrés, Embarcación y Misión Chaqueña (Salta), /a/ y /a/ se neutralizan en contacto con la consonante velar (cf. Tovar, 1958, 1981, Viñas Urquiza, 1974). Estas son consideradas zona de transición.

La variable 3 es morfológica: el pronombre de primera persona singular. La variación en este pronombre fue identificada desde el siglo XIX por Lafone Quevedo (1895, 1896b, 1897) y más tarde, en otro estadio evolutivo, señalada por Viñas Urquiza (1974) y Messineo y Braunstein (1990). A partir de la distribución geográfica de las variantes actuales, observamos que en el grupo pilcomayeño se usan las formas olham 'olhaam y $0^{-}$'oo-, que denominaremos 'formas en $0^{-}$', mientras que en el grupo bermejeño, los pronombres son n'lham y $n^{\prime}$-, que denominaremos 'formas en $n^{\prime}-$ '. Como ocurre con los rasgos fonológicos, hay zonas de transición que presentan la coexistencia de formas en 0 - y formas en $n$-. En San Andrés y Embarcación (Salta) y en El Palmarcito y María Cristina (Formosa), se usa el pronombre libre olham, pero para los pronombres ligados, se usa $0^{-}$y no-, en las localidades salteñas, y $0^{-}$y $n^{\prime}$-, en las localidades formoseñas. Por el momento, no hemos encontrado el criterio para su distribución entre los verbos. En la sección 4 examinaremos la evolución de los pronombres ligados que dio lugar a las variantes descriptas.

La variable 4, el pronombre ligado que indica persona poseedora indefinida, es un hallazgo novedoso para los estudios de la variación en wichí/weenhayek. Dicho pronombre se usa en los sustantivos inalienables cuando no se especifica quién es el poseedor, por eso generalmente su traducción es 'de alguien'. En el grupo pilcomayeño, la forma de este pronombre es 'noon'o- (p.ej., n'oko 'madre de alguien'), mientras que en el grupo bermejeño, es to- (p.ej., toku 'madre de alguien'). Los paradigmas que emplean las formas no- y to- 'POS. INDF' incluyen las variantes $o^{-}$y $n^{\prime}$ - de primera persona respectivamente. Sin embargo, en la zona de Coronel Juan Solá (Morillo) en la provincia de Salta (en misión Los Baldes, y los barrios La Cortada, Primavera y Cacique Catán de Morillo), el paradigma de persona posesivo incluye la variante 0 - para la primera persona singular y las dos variantes del indefinido no- y tä- (cf. Montani, 2017 p. 489). La fuente que dio origen al desarrollo de las variantes to- $\sim$ tä- todavía está bajo estudio, por 
el momento se observa un uso bastante uniforme en cada grupo y ciertas semejanzas con algunas formas pronominales indefinidas en otras lenguas mataguayas: 'POSEEDOR INDEFINIDO' vat- y con menor frecuencia tin- $\sim$ tn-, na- $\sim n$ - en nivaĉle (Fabre, 2014 p. 80 y 82), (i) $n$ - (y $t(V)$ - para el impersonal verbal) en chorote (Carol, 2014 p. 361), y wit- y con menor frecuencia $n$ - en maká (Gerzenstein, 1994 p. 147, nota al pie 41).

La variación del objeto pronominal en los verbos, la variable 5, es otro rasgo morfológico que no había sido considerado hasta el momento, discutido en Nercesian (2019a). Cuando el objeto de una oración está expresado mediante un pronombre de primera o segunda persona, como en castellano 'me' en 'Vos me enseñás', o 'te' en 'Yo te enseño', en wichí/weenhayek se indica con un pronombre que va ligado al verbo, en lugar de ser una palabra independiente como en castellano. Adelantamos este aspecto en la sección 2. Cuando el pronombre que expresa el objeto de la oración es de primera persona, siempre es un sufijo $-n^{\prime} o$ (Pyo) $\sim-n^{\prime} u$ (Bjo), como en (6). Pero cuando el pronombre es de segunda persona, ese es un prefijo en el pilcomayeño y un sufijo en el bermejeño, como en (7).

\begin{tabular}{|c|c|c|}
\hline (6) & Pilcomayeño. & $\begin{array}{l}\text { la-chufwan-n'o } \\
\text { vos-enseñar-me } \\
\text { 'Vos me enseñás.' }\end{array}$ \\
\hline & Bermejeño. & $\begin{array}{l}\text { la-chefwen-n'u } \\
\text { vos-enseñar-me } \\
\text { 'Vos me enseñás.' }\end{array}$ \\
\hline (7) & Pilcomayeño. & $\begin{array}{l}\text { o-a-iw'en } \\
\text { yo-te-ver } \\
\text { 'Te veo.' }\end{array}$ \\
\hline & Bermejeño. & $\begin{array}{l}n^{\prime} \text {-w'en-'am } \\
\text { yo-ver-te } \\
\text { 'Te veo.' }\end{array}$ \\
\hline
\end{tabular}

Dado que la posición preverbal del pronombre de objeto en la estructura morfológica del verbo es una propiedad que se encuentra en otras lenguas mataguayas (ejemplos en (3)), especulamos que este es un rasgo que el wichí/ weenhayek heredó del proto-mataguayo y que el cambio debió darse sólo en el grupo bermejeño, regularizando el sistema de marcación siempre posverbal. El modelo para esta regularización pudo haber sido, o bien la estructura con el sufijo de primera persona como en (6), o bien las construcciones con direccionales y locativos en las que el pronombre de segunda persona es posverbal en los dos complejos dialectales, como vimos en (4), o bien las dos cosas.

A modo de síntesis, la Tabla 2 muestra la lista de rasgos o variables que definen los complejos dialectales, las variantes para cada una de ellas, y las zonas de transición.

La variación en el pronombre de primera persona libre, olham (Pyo) n'lham (Bjo), y su correspondiente ligado, $0^{-}$(Pyo) $\sim n^{\prime}$ - (Bjo), es resultado de un cambio interno en ambos grupos. Pero con relación a las otras variables, teniendo en cuenta los rasgos de la familia mataguaya, el bermejeño parece haber introducido los cambios lingüísticos fonológicos (como la aspiración de consonantes y la neutralización del contraste /a/-/a/) y morfológicos (como el desarrollo de la forma posesiva indefinida en to- y la regularización de la marcación del objeto de segunda persona como sufijo). Por este motivo, decimos que el grupo bermejeño (y dentro de ese, el abajeño en particular, como veremos 3.2) es el grupo innovador del cambio lingüístico. Ingham (1982) y, más tarde, Trudgill (2011), destacaron la importancia del rol de la periferia vs. contacto para la explicación de los procesos de cambio lingüístico que resultan en variantes diferentes. Aquellos dialectos más aislados tienden a ser más conservadores que los que se encuentran más próximos o en contacto con otras lenguas y dialectos. El mismo principio es sostenido por quienes abogan por la lingüística del espacio (Bonfante, 1947). Aunque también se han registrado casos en los que los grupos más periféricos son los innovadores del cambio, como ocurrió en Inglaterra con la pérdida de la /j/ (cf. Chambers y Trudgill, 1998). En el caso del wichí/weenhayek, es difícil aún determinar con precisión la situación, puesto que si bien el grupo bermejeño (y particularmente el abajeño) es más periférico respecto del "centro mataguayo", también es más central con respecto al "centro chaqueño".

\subsection{Río arriba, río abajo: la variación al interior de los complejos pilcomayeño y bermejeño}

Al interior de los complejos dialectales pilcomayeño y bermejeño pueden reconocerse a su vez subdivisiones que, siguiendo los antecedentes en el tema, denominamos 'arribeño' y 'abajeño', según su ubicación geográfica en relación al curso de los ríos. Entre los antecedentes, Gerzenstein $(1992,2003)$ había utilizado estos términos para distinguir dos parcialidades wichí en las localidades de Las Lomitas y Juan Gregorio Bazán (Formosa), las cuales presentan pocas diferencias entre sí. ${ }^{5}$ Según la autora, las comunidades de Lote 42, 47, 27 y Tres Pozos son arribeños o phomleley y Colonia Muñiz y Pantalla, abajeños o chomleley. Como observaron Messineo y Braunstein (1990), "arribeño" y "abajeño" son términos posicionales y relativos a la ubicación determinada por el eje NO-SE del río Bermejo, empleados por las bandas. Según Montani (2017 p. 92), este es un criterio topológico o geográfico de distinción de grupos sociales.

\footnotetext{
5 Gerzenstein (1992) refirió a estas dos parcialidades a partir del testimonio de un informante, y las diferencias lingüísticas anotadas fueron las que este le manifestara de manera espontánea a la autora. Por este motivo, es necesario ampliar la representatividad de datos lingüísticos.
} 
Tabla 2. Rasgos estructurales de variación entre los complejos pilcomayeño y bermejeño.

Table 2. Structure features of variation between the Pilcomayeño and Bermejeño groups.

\begin{tabular}{|l|l|l|l|}
\hline & Pyo & Bjo & Zonas de transición \\
\hline $\begin{array}{l}\text { 1. Desarrollo de serie aspirada } \\
\text { (oclusivas y nasales y } \\
\text { semiconsonantes) }\end{array}$ & gc o fonética & fonémica & $\begin{array}{l}\text { San Andrés, } \\
\text { Embarcación }\end{array}$ \\
\hline 2. Contraste /a/-/a/ & sí & no & $\begin{array}{l}\text { Misión La Paz, San } \\
\text { Andrés, Embarcación, } \\
\text { Misión Chaqueña }\end{array}$ \\
\hline 3. Pronombre 1 pers. (libre y ligado) & o-forma & n-forma & $\begin{array}{l}\text { San Andrés, El } \\
\text { Palmarcito, María } \\
\text { Cristina }\end{array}$ \\
\hline $\begin{array}{l}\text { 4. Desarrollo de to-forma 1 pers. } \\
\text { indefinida }\end{array}$ & no & sí & $\begin{array}{l}\text { Misión Los Baldes, Bo. } \\
\text { La Cortada, Bo. } \\
\text { Primavera y Bo. } \\
\text { Cacique Catán de } \\
\text { Morillo (Coronel Juan } \\
\text { Solá -Morillo-) }\end{array}$ \\
\hline 5. Objeto de 2pers. prefijante & sí & no & \\
\hline
\end{tabular}

En nuestro estudio, recuperamos estas denominaciones para nombrar grupos geolectales según la distribución de las formas lingüísticas en relación a los ríos. Dado que el análisis contempla la variación dialectal en todo el territorio de habla, la referencia para los términos "arribeño" y "abajeño" no es coincidente con la utilizada en Gerzenstein (1992, 2002), que se acota a una zona particular.

Inicialmente, analizamos la distribución geográfica de las variantes de cinco variables lingüísticas que definieron el subgrupo bermejeño abajeño diferenciado del arribeño

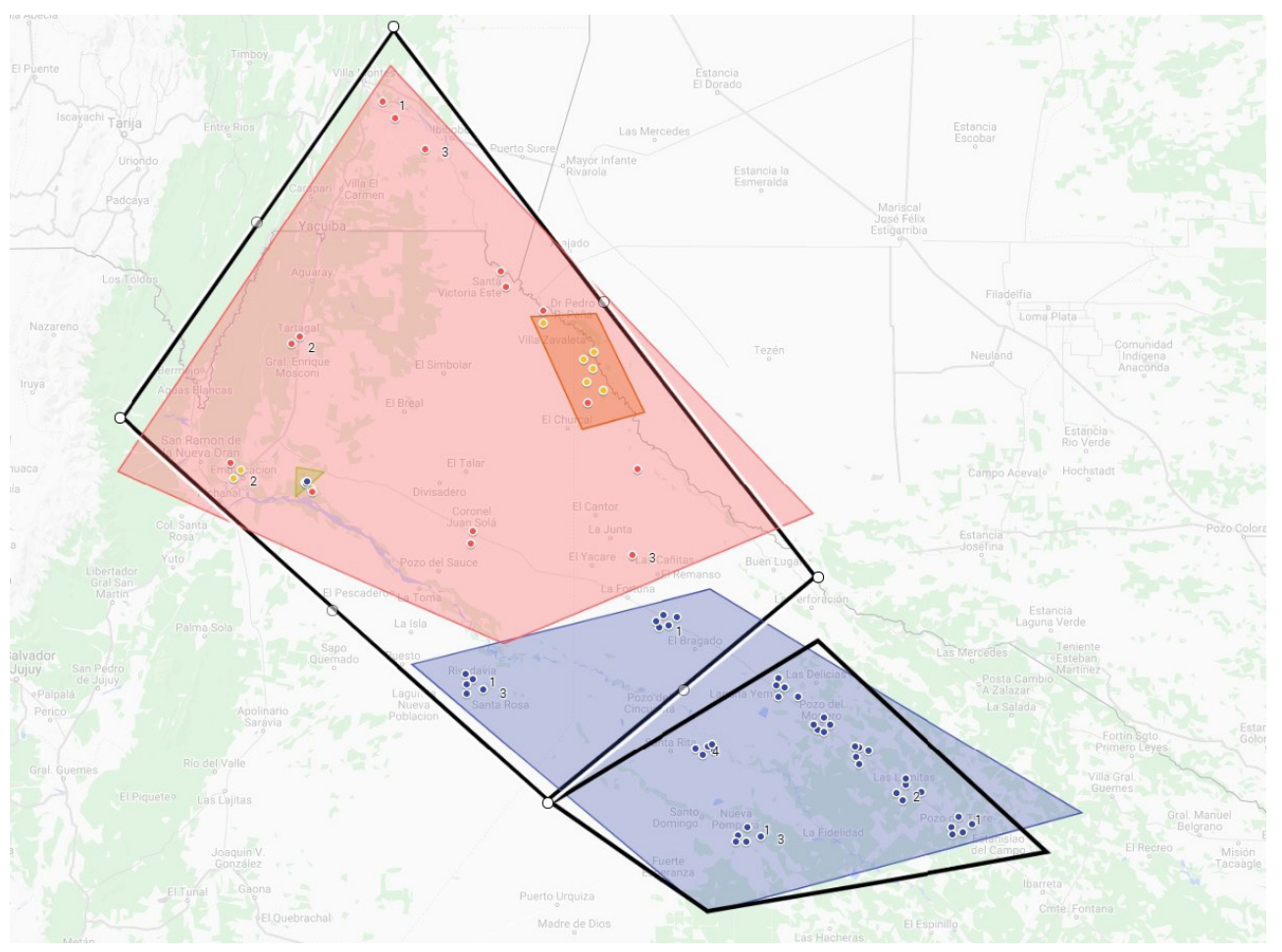

Figura 2. Subdivisión de los complejos dialectales pilcomayeño (rojo) y bermejeño (azul) en arribeños y abajeños según isoglosas lingüísticas. En líneas negras, la isoglosa sudeste corresponde al bermejeño abajeño y la noroeste, al grupo pilcomayeño y el subgrupo bermejeño arribeño.

Figure 2. Pilcomayeño (red) and Bermejeño (blue) dialectal groups subdivision into arribeños y abajeños according to linguistic isoglosses. In black lines, the south-eastern isogloss corresponds to the south-eastern isogloss corresponds to the Bermejeño Abajeño dialectal subgroup, and the north-western isogloss corresponds to the Pilcomayeño dialectal group and the Bemejeño Arribeño subgroup. 
y del complejo pilcomayeño (Figura 2). Las variables son las siguientes: (i) serie de consonantes nasales y semiconsonantes glotalizadas; (ii) estatus fonémico de $/ \mathrm{x}^{\mathrm{w}} /$ y /fw/; (iii) estatus fonémico de /kj/y /č/; (iv) palatalización como proceso fonológico; y (v) morfema de negación realis.

En relación con la variable (i), el desarrollo de la serie de nasales y semiconsonantes glotalizadas se registra actualmente sólo en la zona baja del río Bermejo en las provincias de Formosa y Chaco, Argentina. Al igual que con las consonantes aspiradas, los pares mínimos contrastivos entre las plenas /n/, /m/, /j/, /w/ y las glotalizadas /'n/, /'m/, /'j/, /'w/ son cuasi mínimos: mak [maq] 'cosa' / m'a ['ma] 'mancha'; nomhi [nomi] 'no viene' / n'omhi ['nomi] 'se desprendió'; chalaj [čalax] 'es negro' / chal'a [ča'la] 'lagartija'; n'yoyen [njojen] 'le doy de beber' / n'y'oyen [n'jojen] 'lloro por algo'; lawuye [lawuje] 'vos hacés algo' / law'uyis [la'wujis] 'tu sangre'. Este podría ser un indicio de un estado tardío de desarrollo de la serie, sumado al hecho de que tampoco se ha difundido hacia el bermejeño arribeño o a zonas del pilcomayeño. En Misión Chaqueña, Viñas Urquiza (1978) apenas había registrado una variante alofónica glotalizada de la nasal alveolar [n'], que casualmente o no es la más frecuente en el abajeño. Las secuencias glotal-nasal/glotal-semiconsonante, en cambio, se encuentran como grupo consonántico en el extremo norte de la cadena dialectal, en Villamontes, Bolivia, y como combinación fonotáctica posible en otras zonas del grupo pilcomayeño, como Misión La Paz y Misión Chaqueña. Quiere decir que existían en la lengua contextos favorables para el desarrollo de esta serie. Las innovaciones del bermejeño abajeño en el inventario fonológico tienden a una simetría. Existiendo una serie de consonantes sordas eyectivas, se desarrolla una serie de sonorantes; y si hay una serie de sonorantes aspiradas y de oclusivas sordas eyectivas, emerge otra de sonorantes glotalizadas.

Otro rasgo fonológico que parece haber sido introducido por el grupo bermejeño abajeño es la fonologización de $/ \mathrm{fw}^{\mathrm{w}} /$, variable (ii). La variación $\left[\mathrm{f}^{\mathrm{w}}\right] \sim\left[\mathrm{x}^{\mathrm{w}}\right]$ fue identificada por Najlis (1968) y la distribución que había sistematizado coincide en parte con la que podemos delinear hoy con un corpus de fuentes mucho más amplio. Existen al menos tres variantes para este sonido $\left[\mathrm{fw}^{\mathrm{w}}\right] \sim\left[\mathrm{x}^{\mathrm{w}}\right] \sim\left[\mathrm{h}^{\mathrm{w}}\right]$. En el grupo pilcomayeño y bermejeño arribeño predominan las realizaciones posteriores labializadas como fonema, la velar $/ x^{w} /$ o la glotal $/ \mathrm{h}$ w/. En cambio, en el grupo bermejeño abajeño se produjo un adelantamiento del punto de articulación hacia el labial, /fw/, en el que predomina el rasgo anterior. En esta variedad, [ $\left.\mathrm{x}^{\mathrm{w}}\right]$ es un alófono de /fw/. En la distribución de estas realizaciones también encontramos una zona de transición. En San Andrés y Embarcación (Salta), Tovar (1981) analizó las realizaciones velar labializada y bilabial labializada como fonemas, porque no alternan en final de palabra, aunque sí lo hacen en otros contextos aparentemente por razones estilísticas. En Rivadavia Banda Norte (Salta), Fernández Garay y Spinelli (2009) observaron una alternancia libre de $/ \mathrm{x}^{\mathrm{w}} /$ con $\left[\mathrm{f}^{\mathrm{w}}\right]$ en posición inicial de palabra, y con [hw] en posición intervocálica.

La distribución de las variantes [č $]$ y [kj] -variable (iii)- es similar a la de $\left[\mathrm{fw}^{\mathrm{w}}\right]$ y $\left[\mathrm{x}^{\mathrm{w}}\right]$. En las mismas zonas en las que el punto velar de $\left[\mathrm{x}^{\mathrm{w}}\right]$ se adelantó al labial [ $\mathrm{fw}^{\mathrm{w}}$ ] (como fonema o como alófono), el punto velar de [kj] se adelantó al palatal [č]. La variación [č] $\sim$ [kj] fue señalada por Najlis (1968), y la correspondencia que mencionamos también puede verse en su análisis. Observamos que la variante africada palatal parece haberse difundido mucho más que la fricativa labiodental/bilabial labializada y haber alcanzado un grado de fonologización mayor. Mientras que el grupo bermejeño abajeño presenta de manera casi uniforme la realización [č] (Gerzenstein 1992, Nercesian 2014), en el bermejeño arribeño se mantiene el uso velar palatalizado [kj] (Terraza 2009a y b), al igual que en el extremo norte del continuum dialectal, en Villamontes (Claesson, 1994) y que en Misión La Paz (Avram 2008). En tanto, las zonas de San Andrés, Embarcación, Misión Chaqueña y Rivadavia Banda Norte (Lapacho Mocho y Misión Santa María, Tartagal, y Santa Victoria Este), en Salta, la consonante palatal africada /č/ se ha difundido con estatus fonémico (cf. Viñas Urquiza, 1974, Tovar, 1981, Fernández Garay y Spinelli, 2009). En Rivadavia Banda Norte, /č/ tiene un alófono en variación libre palatalizado [č̉]. Para las zonas de San Andrés y Embarcación, Tovar afirma que la africada palatal "parece resultado de la palatalización de $q$. En realidad, en la lengua actual esta evolución no ha terminado y la forma anterior con $q$ y la palatalizada coexisten" (1981 p. 170). La variante velar palatalizada debió ser la más antigua y haber sufrido un adelantamiento al punto palatal, posiblemente originado en el bermejeño abajeño y luego difundido hacia el resto de las zonas. En el bermejeño abajeño, la /č/ ya está fonologizada, a diferencia de las zonas de transición que presentan una alternancia con la velar. Además, Remedi (1896) había registrado la /kj/ para la variedad entonces denominada "mataco" (sudoeste del territorio wichí/weenhayek) con la siguiente descripción: "A su alfabeto faltan cuatro letras del nuestro y son: $C h$, $D, G, R$ y tiene una letra sin equivalente en el nuestro que yo suplo con la $C k$ y se pronuncia arrimando la lengua al paladar" (Remedi, 1896 p. 353).

Esta tendencia al adelantamiento del punto de articulación se observa en el bermejeño abajeño que presenta palatalización, variable (iv), no analizada hasta ahora. Se trata de un proceso fonológico en el cual un sonido se vuelve palatal por estar en contacto con otro que se pronuncia en esa zona de la boca. Las consonantes velares $[\mathrm{x}] \mathrm{y}[\mathrm{k}]$ que se encuentren entre dos vocales y seguidas de las vocales anteriores [i] o [e] se vuelven palatales: [x] $<j>\rightarrow\left[\int\right]<s h>$ y $[k]<k>\rightarrow[\check{c}]<c h>$. En (8), presentamos un ejemplo con palatalización y sin palatalización. 
(8)

[jik] yik 'se va' + [-hen] -hen 'plural'

$>$ Pyo, Bjo.arr. [jik'en] yikhen 'se van'

$>$ Bjo. ab. [jıčnen] yich"en 'se van'

La palatalización (histórica y sincrónica) es un rasgo extendido en las lenguas chaqueñas, y las guaycurúes presentan el mismo tipo de proceso que el wichí (Nercesian, 2011, González, 2014). Existe la posibilidad de que el bermejeño abajeño hubiera incorporado la palatalización como proceso sincrónico por contacto con los pueblos guaycurú en Chaco y Formosa. Sin embargo, el grado de estabilidad de las comunidades está íntimamente relacionado con la localización de periferia o de contacto de la variedad; los dialectos periféricos suelen ser más estables. Como mencionamos antes, deberá discutirse este principio a la luz de la realidad chaqueña, y definir, para este caso particular, qué es centro y qué es periferia en términos sociolingüísticos para el wichí/ weenhayek.

Por último, el morfema de negación del modo realis, variable (v), es un rasgo de variación entre el bermejeño abajeño y el resto de los grupos que tampoco se había estudiado. En el bermejeño arribeño y el pilcomayeño, el morfema de negación es -hit'e -hit' $a$. En el bermejeño abajeño, en cambio, si bien se encontraron ocurrencias de este morfema, la forma más frecuente es ha-...-hi (cf. Nercesian, 2008, 2011, 2014). Compare ejemplos en (9).

(9) Pyo.arr.

'imaak-'is-hit'ah

cosa-es.bueno,a-NEGACIÓN

'It is insignificant.' ['es insignificante']

(Claesson, 1994 p. 30)

Bjo.arr. $\quad t^{\prime}$ en-hit'e

es.duro,a-NEGACIÓN

'Es blando, a.' (Terraza, 2009 p. 39)
Bjo.ab. ha-'atha-hi

NEGACIÓN-es.fácil-NEGACIÓN

'Es difícil.' (Nercesian, 2014 p. 317)

Desde la dialectología se afirma que, generalmente, si de dos formas una es usada dentro de un área más amplia que la otra, entonces esa es más antigua (Chambers y Trudgill, 1998). De acuerdo con los rasgos analizados y su extensión geográfica de uso (Tabla 3), la ausencia de fonemas nasales y semiconsonantes glotalizadas, el estatus fonológico de $/ x^{w} /$, el estatus fonológico de $/ \mathrm{k} \mathrm{j} /$, la ausencia de palatalización y la negación -hit'e $\sim$-hit'a, que están presentes en el complejo pilcomayeño y en el bermejeño arribeño, debieran ser los rasgos más antiguos porque están presentes en una extensión geográfica mayor que los del bermejeño abajeño.

El Tabla 3, sistematiza las variables analizadas. Según la distribución de las variantes, sugerimos que los rasgos lingüísticos del bermejeño abajeño debieron haber evolucionado en un tiempo relativamente reciente, dado que no han llegado a difundirse hacia el resto del grupo bermejeño u otras zonas (como sí sucedió con los analizados en la sección anterior) y que en algunos casos coexisten las dos formas.

\section{La lengua wichí/weenhayek a través del tiempo}

El estudio histórico y de reconstrucción interna del wichí/weenhayek es un área muy poco explorada (Nercesian, en prensa; Nercesian, 2019) y, en general, los documentos antiguos que se conocen hasta ahora son escasos y fundamentalmente de la segunda mitad del siglo XIX, con excepción del manuscrito conservado por D'Orbigny, publicado en 1896 en el Boletín Geográfico Argentino por Lafone Quevedo, que habría de ser de autoría del franciscano Primo Ayala y datado

Tabla 3. Rasgos estructurales de variación entre los grupos pilcomayeño y bermejeño arribeño y el subgrupo bermejeño abajeño.

Table 3. Structure features of variation between the Pilcomayeño and Bermejeño Arribeño groups and the Bermejeño abajeño subgroup.

\begin{tabular}{|l|l|l|l|}
\hline & Pyo y Bjo.arr. & Bjo.ab. & Zonas de transición \\
\hline $\begin{array}{l}\text { i. Desarrollo de serie sonora } \\
\text { glotalizada (nasales y } \\
\text { semiconsonantes) }\end{array}$ & no & sí & Misión Chaqueña (?) \\
\hline \begin{tabular}{l} 
ii. Estatus fonémico de $\left[\mathrm{x}^{\mathrm{w}}\right]$ y $\left[\mathrm{f}^{\mathrm{w}}\right]$ \\
\hline iii. Estatus fonémico de $\left[\mathrm{k}^{\mathrm{j}}\right]$ y [č]
\end{tabular} & $/ \mathrm{x}^{\mathrm{w} /} / \mathrm{k}^{\mathrm{j} /}$ & $/ \mathrm{f}^{\mathrm{w}} /,\left[\mathrm{x}^{\mathrm{w}}\right]$ & San Andrés y Embarcación \\
\hline $\begin{array}{l}\text { iv. Palatalización (con cambio en } \\
\text { el punto de articulación) }\end{array}$ & no & $/ \check{c} /$ & $\begin{array}{l}\text { San Andrés, Embarcación, } \\
\text { Misión Chaqueña, Rivadavia } \\
\text { Banda Norte }\end{array}$ \\
\hline v. Negación realis & $-h i^{\prime} e \sim-h i t^{\prime} a$ & $\begin{array}{l}\text { ha-...-hi } \\
\left(-h i t^{\prime} e\right)\end{array}$ & \\
\hline
\end{tabular}


hacia fines del siglo XVIII (cf. Combès y Montani, en este dossier). No obstante, en tanto contamos con documentación antigua, actual y de etapas intermedias, se puede empezar a formular algunas hipótesis evolutivas. Un siglo es tiempo suficiente para que una lengua experimente cambios internos. Por otro lado, la búsqueda de materiales antiguos no se agotó; existen expectativas de hallar nuevos registros.

En la sección 3.1, vimos que las diferencias fonológicas y morfológicas, que presentan mayor grado de difusión, se encuentran entre los complejos pilcomayeño y bermejeño, y que esto sugeriría que son las variedades con mayor tiempo de divergencia. Si bien al momento actual no estamos en condiciones de estimar esta divergencia en años, la profundización en el estudio del sistema pronominal puede arrojar algo de luz.

Un rasgo de variación analizado entre el complejo pilcomayeño y el bermejeño es el pronombre de primera persona sujeto: formas en $o^{-}$en el pilcomayeño y formas en $n$ - en el bermejeño. En los registros de fines del siglo XVIII, se documentó el prefijo no-, y especulamos que las variantes $o^{-}$y $n^{\prime}$ - provengan de esa antigua forma. Hunt (1913) pone en relación las tres variantes para la primera persona no-, $\mathrm{O}^{-}$y $\mathrm{n}^{-}$, aunque sin una interpretación histórica evolutiva. El registro de los grupos vejoces en el manuscrito conservado por d'Orbigny (Lafone Quevedo, 1896), cuya autoría se le adjudica al franciscano Primo Ayala a fines del siglo XVIII, corresponde a la zona oeste en la margen izquierda del río Bermejo, y atestigua los prefijos no-, en raíces que inician con consonante, y $n$ - en raíces que inician con vocal: no-Quiin 'tener sed' (Lafone Quevedo 1896 p. 161), n-Upa 'salir' (Lafone Quevedo, 1896 p. 163). En el siglo XIX, las anotaciones gramaticales de Massei (1895) sobre la variedad weenhayek (o noctén), en la zona del Pilcomayo alto, atestiguan los prefijos na- y no-: Nonayej 'Yo lo amo', No-quiaj 'Yo lo llevo' (Massei, 1895 p. 352). Las observaciones de Remedi (1896), sobre la variedad usada por el grupo denominado 'mataco', atestiguan los mismos prefijos que los vejoces, en el s.XVIII," no- $\sim$ nu- y $n$-, en la misma distribución: n-ichém 'tengo sed' (Remedi, 1896 p. 358), nu-nuhuáya 'tengo, tenemos miedo' (Remedi, 1896 p. 359). Por último, los registros de Pelleschi (1897) de los grupos denominados "matacos occidentales del Bermejo", atestiguan los prefijos nu-, no-, ni- y $n$ - (ante raíz con vocal inicial): nu-huén 'veo', nu-isset/nissét 'corto'. En el siglo $X X$, ya se documentan las dos formas que se usan actualmente para la primera persona, y se constatan en el siglo XXI: O- (Hunt, 1913, 1940; Najlis, 1968; Viñas Urquiza, 1974; Alvarsson, 1979; 1984; Claesson, 1994; Lunt, 1999; DIRLI, 2003) y $n^{\prime}$ - (Golluscio, 1980; 1993a y b; Terraza, 2009a; Nercesian, 2011). En hablantes de la comunidad de Palmarcito (Ramón Lista, Formosa; grupo pilcomayeño abajeño) existe una variación entre los dos prefijos: en algunos predicados transitivos emplean, de manera obligatoria y sin condicionamiento fonológico, el prefijo $n$ - en lugar de $0^{-}$. Así pues, podemos especular que la divergencia en la marcación morfológica de la primera persona sujeto debió haber ocurrido entre fines de siglo XVIII y la primera mitad del siglo XX.

A partir de estas evidencias, habrían al menos tres etapas evolutivas. Una temprana: las variantes no- y nu- se empleaban en todos los contextos. Una segunda etapa (desde, al menos, fin de siglo XVIII hasta primera mitad de siglo $X X)$ : coexistencia de forma antigua y la reducida $n$ - según zonas geográficas, y variantes no- y $n$ - con distribución complementaria dependiendo del contexto fónico. En la parte alta del río Pilcomayo, los grupos "noctenes" empleaban la forma no-; y en las zonas baja del Pilcomayo, alta del Bermejo y media del Bermejo los grupos "matacos", "vejoces" y "matacos occidentales" empleaban las variantes no- y nu-con raíces que inician en consonante, y $n$ - en raíces que inician en vocal. Una tercera etapa (desde mediados del siglo $\mathrm{XX}$ ): desuso de la forma antigua no- $\sim n u^{-}$, y de variantes en distribución complementaria, divergencia diatópica estable en todos los contextos fónicos. Los grupos pilcomayeños emplean siempre $o$ - (excepto un grupo abajeño que presenta una distribución estable y aparentemente lexicalizada) y los grupos bermejeños, siempre $n$ - o $n^{\prime}$-.

Otro rasgo de variación pronominal que vimos en 3.1 es la posición del objeto de segunda persona en el verbo. En el pilcomayeño, es un prefijo, pero en construcciones con direccionales y locativos, es un sufijo, (10).

$\begin{array}{ll}\text { Pilcomayeño. } & \text { 'o-a-ikyen } \\ & \text { yo-te-mandar } \\ & \text { 'Yo te mando.' } \\ & \text { (Alvarsson, 1984: 34) } \\ & \text { 'o-t'u-am-e } \\ \text { Pilcomayeño. } \quad & \text { yo-mirar-te-LOCATIVO } \\ & \text { (Alvarsson, 1984: 34) }\end{array}$

Esta variación se registra en la lengua desde mediados de siglo XIX, ejemplos (11). Por eso especulamos que el uso posverbal del pronombre de segunda persona es muy antiguo.

$$
\begin{aligned}
& \text { Mataco. Nu-a-ilon-lá } \\
& \text { yo-te-matar-FUTURO } \\
& \text { 'Te mataré.' (Pelleschi 1987, p. 183) } \\
& \text { Mataco. a-Huoc-on-am-e } \\
& \text { a-Huoc on-am-e } \\
& \text { tu-dueño grita-te-LOCATIVO.cerca } \\
& \text { 'Te llama tu patrón.' } \\
& \text { (Lafone Quevedo, 1896a, p. 357) }
\end{aligned}
$$

Construcciones como las de (11) también se encuentran 
en el resto de las lenguas mataguayas (cf. (4)). A partir de los cognados sintácticos, de los documentos antiguos y los datos actuales, especulamos que la evolución del prefijo y del sufijo de objeto se dio en momentos diferentes y a partir de procesos y fuentes distintas. La gramaticalización del prefijo, $a$ - 'te', habría evolucionado a partir del pronombre libre am: $a-<a m$, y el sufijo, como resultado del reanálisis de construcciones de verbos seriales (construcciones sintácticas que se forman por una cadena de verbos como la de (12)).

\section{Bermejeño abajeño. $\begin{array}{lll}n^{\prime} \text {-nay } & n^{\prime} \text {-ihi } & \text { tewukw } \\ \text { yo-bañarse } & \text { yo-estar.en } & \text { río }\end{array}$} 'Me baño en el río.' [lit. 'me baño estoy en el río'] (Nercesian, 2009/2010 pp. 213)

El reanálisis es un proceso mediante el cual una determinada construcción es reinterpretada por los hablantes como un nuevo tipo de construcción (Gildea, 2002 pp. 317-318). Es un proceso gradual, que crea polisemia (los morfemas añaden un nuevo significado/función al original) y afecta a la construcción entera (no cambia un solo elemento, sino también otros relacionados en la misma construcción). Las construcciones de verbos seriales habrían sido el ámbito para la evolución de verbos como 'estar en' en partícula locativa 'en', (13), esto es, una gramaticalización.

$$
\begin{aligned}
& \text { Bermejeño abajeño. } \\
& n \text { '-nay-hi tewukw } \\
& \text { 1suj-bañarse-loc.en río } \\
& \text { 'Me baño en el río.' (Nercesian, 2009/2010 p. 213) }
\end{aligned}
$$

En Nercesian (2019) se argumenta que originalmente las construcciones de verbos seriales se formarían con el pronombre libre en la función de sujeto antepuesto a verbos que indican locación o dirección. Por eso, el sufijo de objeto es -am y no $a^{-}$.

En una segunda etapa, posiblemente desde el protomataguayo, durante el período de divergencia entre las lenguas, o posteriormente y difundido en toda la familia, se habría iniciado el proceso de gramaticalización de los verbos de locación y dirección como posposición ligada al pronombre; p.ej. nú-ho 'para mí; ám-u o ham-u 'para vos'; núj-a 'me'; am-a 'te' (Pelleschi 1886 p. 294). Dado que el verbo habría perdido sus propiedades al gramaticalizarse, el pronombre que era sujeto se habría reanalizado como objeto del verbo principal de la serie, dando como resultado construcciones como la de (14). En este ejemplo, el pronombre no- ligado a la partícula -ye es el objeto del verbo quiotte 'ayudar'.

\section{(14) Nocten.}

Quiotte noyegen noquieuye eñil.

quiotte no-ye-gen

ayudá me-LOCACIÓN-PL

no-quieu-ye eñi-l

yo-obedecer-LOCACIÓN palabra-PL

'Ayudanos para que cumplamos tus palabras.'

(Extracto de traducción del Padre Nuestro al wichí, Massei, 1895 p. 353)

En una tercera etapa, que habría sido desde fines de siglo XIX hasta la actualidad, se habría dado un proceso de reanálisis de la posposición como aplicativo (en wichí/weenhayek, pero no en todas las mataguayas) y la aglutinación del complejo [PRO-locativo/direccional] al verbo. El cambio de posposición a aplicativo implica que la partícula locativa ya no se añade al sustantivo o al pronombre sino al verbo. Actualmente, las construcciones con aplicativo (APL) se encuentran en todas las variedades y representarían un estado avanzado del proceso. Véase lachufwen'oyej y n't'on'amche en (15).

\section{Pilcomayeño arribeño la-chufwen-n'o-yej vos-enseñar-me-APL}

ta

CONJ.REALIS

'Me enseñaron otras cosas sobre las costumbres.'
Bermejo abajeño

$n^{\prime}$-t'on-'am-che

yo-gritar-te-APL

'Te grito/llamo a gritos (te estás alejando).'

(Nercesian, 2014 p. 256)

Finalmente, en una cuarta etapa, entre mediados del siglo XIX (quizá incluso fines del XVIII) y principios del $X X$, se habría iniciado el proceso de regularización del objeto sufijante en la variedad bermejeña. Esta etapa habría de ser la misma en que tuvo lugar la divergencia del pronombre de primera persona entre el pilcomayeño y el bermejeño, descripto antes. El lapso desde fines de siglo XVIII y principios del XX parece haber sido el tiempo en que algunos pronombres se gramaticalizaron, y este proceso fue dispar en las distintas zonas de habla wichí. Entre fines del siglo XIX y fines del XX, el prefijo de segunda persona objeto se extendió en el grupo pilcomayeño, y a principios de este siglo, ya se encuentra estable como sufijo en el bermejeño.

En el plano de la fonología, por el momento, y sin posibilidades de periodizar etapas evolutivas, hemos formulado algunas hipótesis que se adelantaron en la sección anterior. La evolución de las series de consonantes aspiradas y nasales y semiconsonantes glotalizadas debió haber ocurrido en momentos distintos. Si en Rivadavia (Bermejo arribeño), la tendencia es a la neutralización de las aspiradas y en el bermejeño abajeño la misma serie está fonologizada, quiere decir 
que ya existían en todo el complejo bermejeño con estatus fonémico. En el pilcomayeño, en cambio, no parece haber indicios de que esta serie hubiera tenido valor fonémico (se documentaron grupos consonánticos o alófonos en posición final de palabra o por contacto con una consonante sorda). Las aspiradas tampoco fueron reconstruidas en el proto-mataguayo. En cuanto a las sonorantes glotalizadas, como se dijo, debió haber sido una innovación tardía en el bermejeño abajeño, tendiendo a una simetría con la serie de eyectivas y aspiradas en el sistema.

\section{Palabras finales}

En este trabajo hicimos un recorrido de la lengua wichí/ weenhayek en una perspectiva filogenética, dialectal y diacrónica interna. Los rasgos que el wichí/weenhayek comparte con el resto de las lenguas de la familia permiten identificar cuáles son las variantes innovadoras en el wichí/weenhayek. Mostramos que al menos un conjunto de cinco rasgos fonológicos y morfológicos diferencian los complejos dialectales pilcomayeño y bermejeño, que tendrían mayor tiempo de divergencia. Y otros cinco, a su vez, diferencian el bermejeño abajeño respecto del arribeño y el pilcomayeño. Con esto mostramos que existirían capas o niveles de variación dialectal que se habrían dado en momentos distintos y con diferente grado de difusión. Finalmente, con una perspectiva histórica, presentamos algunas hipótesis evolutivas que explican la variación en sincronía.

Este estudio de la variación en espacio y tiempo no está acabado. Se encuentra en curso la tarea de ampliar el análisis hacia otros rasgos de variación, y los niveles léxico y sintáctico. Asimismo, la de profundizar el estudio de la historia de la lengua y su filogénesis. Pero consideramos que estos resultados aportan nuevos conocimientos para esclarecer la compleja e interesante trama de la lengua wichí/weenhayek.

Berisso, 21 de abril de 2020

\section{Agradecimientos}

Agradezco a los evaluadores anónimos por los valiosos aportes que generosamente brindaron y enriquecieron este trabajo. Asimismo, agradezco a mis colegas Alejandra Vidal, Analía Gutiérrez y Adriana Serrudo, por diversos intercambios sobre algunos aspectos aquí analizados. Los resultados presentados en este trabajo forman parte de una investigación más amplia financiada por el CONICET y la FONCYT, AGENCIA, Ministerio de Ciencia, Tecnología e Innovación Productiva, Argentina (proyectos PICT 2013-2539 y PICT 2016-0593).

\section{Referencias}

Aikhenvald, A. (1999). The Arawak language family. En
Dixon, R.M.W. y Aikhenvald, A. (Eds.). The Amazonian languages (pp. 65-106). Cambridge: Cambridge University Press.

Alvarsson, J.A. (1979). We'hnayek Ihamet. Un manual del idioma mataco-noctenes. Cochabamba: Imprenta indigenista boliviana.

Alvarsson, J.A. (1984). Wenhayek Ihamet. Cochabamba: Misión Sueca Libre.

Avram, M. L. Z. (2008). A phonological description of Wichi: the dialect of Misión La Paz, Salta, Argentina. Tesis de Maestría, Universidad de Michigan del Este. http:// commons.emich.edu/theses/152

Bonfante, G. (1947). The neolinguistic position. Language, 23, 344-375.

Braunstein, J. (1992/93). Territorio e historia de los narradores matacos. Hacia una nueva carta étnica del Gran Chaco, 5, 4-74.

Bynon, T. (1977). Historical Linguistics. Cambridge: Cambridge Textbooks in Linguistics.

Campbell, L. (2000). American Indian Languages: The historical linguistics of Native America. Oxford: Oxford University Press.

Carol, J. 2011. Aplicativos/adposiciones en chorote (mataguayo): algunos aspectos formales. Liames, 11(1). 51-74.

Carol, J. (2014). Lengua chorote (mataguayo). Estudio fonológico y morfosintáctico. München: LINCOM.

Chambers, J. K. y Trudgill, P. (1998). Dialectology. Cambridge: Cambridge University Press.

Claesson, K. (1994). A phonological outline of mataconoctenes, International Journal of American Linguistics, $60,1-37$.

Claesson, K. (2017). Estudios de la gramática del idioma 'weenhayek. http://noctenes.org/the\%20language/ el\%20idioma\%20'weenhayek.html

Comrie, B., Golluscio, L., González, H. y Vidal, A. (2010). El Chaco como área lingüística. En Estrada Fernández, Z. y Arzápalo Marín, R. (Eds.), Estudios de lenguas amerindias 2. Lenguas Indígenas (pp. 84-130). Hermosillo, Universidad de Sonora.

DIRLI [Programa de Desarrollo Integral Ramón Lista]. 2003. Gramática escolar de la lengua wichí. Departamento Ramón Lista, Formosa: Subprograma de Educación. 
Fabre, A. (2005). Los pueblos del Gran Chaco y sus lenguas, segunda parte: Los Mataguayo. Suplemento Antropológico, 40(2), 313-435.

Fabre, A. (2014). Estudio gramatical de la lengua Nivacle. Kangasala: Edición provisional disponible en línea en http://www.etnolinguistica.org/biblio:fabre2014-estudio.

Fernández Garay, A. y Spinelli, S. (2009). Sincronía dinámica del sistema fonológico del wichí hablado en la Banda Norte del Departamento Rivadavia, Salta. En Fernández Garay, A. y Censabella, M. (Comps.). Estudios fonológicos de continua dialectales mapuche y wichí (pp. 145-173). La Pampa: Universidad Nacional de La Pampa.

Gerzenstein, A. (1978). Lengua chorote 1. Buenos Aires: Universidad de Buenos Aires.

Gerzenstein, A. (1989). Lengua maká: Aspectos de la fonología. Buenos Aires: Universidad de Buenos Aires.

Gerzenstein, A. (1992). Una variedad oriental del mataco. Algunos datos fonológicos y morfológicos. Hacia una nueva carta étnica del Gran Chaco, 4, 67-79.

Gerzenstein, A. (1994). Lengua maká. Estudio descriptivo. Buenos Aires: Universidad de Buenos Aires.

Gerzenstein, A. (2003). Variaciones dialectales de algunas unidades del sistema consonántico wichí. En Tisera, A. y Zigarán, J. (Comps.). Lenguas y culturas en contacto (pp. 69-81). Salta: CEPIHA-Universidad Nacional de Salta.

Gerzenstein, A. (2015a). Chorote dictionary. En Key, M.R. y Comrie, B. (Eds.). The Intercontinental Dictionary Series. Leipzig: Max Planck Institute for Evolutionary Anthropology. http://ids.clld.org/contributions/304 .

Gerzenstein, A. (2015b). Maca dictionary. En Key, M.R. y Comrie, B. (Eds.). The Intercontinental Dictionary Series. Leipzig: Max Planck Institute for Evolutionary Anthropology. Disponible en: http://ids.clld.org/ contributions/305.

Gildea, S. (2002). Pre-Proto-Tupí-Guaraní Main Clause Person-Marking. En Arruda Câmara Cabral, A. S. y Rodrigues, A. (Orgs.). Línguas Indígenas Brasileiras. Fonologia, Gramática e Histórica. Actas do I Encontro Internacional do Grupo de Trabalho sobre Línguas Indígenas da ANPOLL (pp. 315-326). Belém/Pará: Editora Universitária UFPA.

Golluscio, L. (1980). Descripción del núcleo gramatical de la lengua wichí (mataco), Variedad hablada en el Teuco (El Sauzalito, Chaco y zona de influencia). Informe de avance. Consejo Nacional de Investigaciones Científicas y Técnicas. MS.
Golluscio, L. (1993a). Clases de sustantivos y sistema cultural: la posesión en wichí. Signo y Seña, 3, 219-239.

Golluscio, L. (1993b). Deixis in wichí. (Ponencia presentada en el Congreso de Society for the Study of Indigenous Languages of the Americas, American Anthropological Association, Washington, 17-21 de noviembre de 1993.)

Golluscio, L. y Vidal, A. (2009-2010). Recorrido sobre las lenguas del Chaco y los aportes a la investigación lingüística. Amerindia, 33/34, 3-40.

González, H. (2015). El Chaco como área lingüística: una evaluación de los rasgos fonológicos. En Comrie, B. y Golluscio, L. (Eds.), Language Contact and Documentation (pp. 165-204). Berlín: Walter de Gruyter.

Greenberg, J. (1987). Language in the Americas. Stanford, California: Stanford University Press.

Gutiérrez, A. (2015). Segmental and prosodic complexity in Nivaĉle: laryngeals, laterals, and metathesis. Tesis doctoral, University of British Columbia.

Gutiérrez, A. y Nercesian, V. (En prensa). La glotal y la glotalizacion en las lenguas mataguayas. Forma y Función 34 (1).

Hunt, R. (1913). El vejoz o aiyo. Revista del Museo de La Plata, 22, 6-215, más mapas y láminas.

Hunt, R. (1940). Mataco grammar. Tucumán: Instituto de Antropología y Universidad Nacional de Tucumán.

INDEC (Instituto Nacional De Estadística y Censos). (2004-2005). Encuesta Complementaria de Pueblos Indígenas. Publicación online: http://www.indec.mecon. ar/webcenso/ecpi/index_ecpi.asp

Ingham, B. (1982). Northeast Arabian dialects. London: Kegan Paul.

Lafone Quevedo, S. A. (1895). Introducción y notas. Grupo mataco-mataguayo del Chaco. Dialecto noctén por Inocencio Massei. Boletín del Instituto Geográfico Argentino, 16, 343-390.

Lafone Quevedo, S. A. (1896a). Prólogo y vocabulario comentado. Los indios matacos y su lengua por Joaquín Remedi. Boletín del Instituto Geográfico Argentino, 17, 331-362.

Lafone Quevedo, S. A. (1896b). Introducción, notas y comentarios. Grupo mataco-mataguayo del Chaco. Dialecto vejoz. Con vocabulario y apuntes de d'Orbigny. Boletín del Instituto Geográfico Argentino, 17(46), 121176. 
Lafone Quevedo, S. A. (1897). Introducción y notas. Los indios mataguayos y su lengua por Giovanni Pelleschi. Boletín del Instituto Geográfico Argentino18 (4-6): 173350.

Lafone Quevedo, S.A (1912). Pronominal classification of certain South American stocks. Buenos Aires: Coni Hnos.

Lunt, R. (1999). Wichí Lhämtes. Salta: Hanne.

Massei, I. (1895). Dialecto noctén. Boletín del Instituto Geográfico Argentino, 16 (9-12), 343-390.

Messineo, C. y Braunstein, J. (1990). Variaciones lingüísticas del mataco. Hacia una nueva carta étnica del Gran Chaco, 1, 1-13.

Messineo, C., Carol, J. y Klein, H. (2016). Deixis y contacto en la región del Gran Chaco: los demostrativos en las lenguas guaycurúes y mataguayas. International Journal of Sociology of Language, 240, 119-157.

Métraux, Alfred. (1996[1946]). Etnografía del Chaco. Asunción: Centro de Estudios Antropológicos de la Universidad Católica.

Milroy, L. y Gordon, M. (2003). Sociolinguistics. Methods and Interpretation. Hong Kong: Blackwell Publishing.

Montani, R. (2017). El mundo de las cosas entre los wichís del Gran Chaco. Cochabamba: Itinerarios.

Montani, R. y Juárez, G. (2016). Ijwalas ta pajche/Los días del pasado. Córdoba: 6, 2016

Najlis, E. (1968). Dialectos del mataco. Anales de la Universidad del Salvador 4, 232-241.

Najlis, E. (1984). Fonología de la protolengua mataguaya. Buenos Aires: Cuadernos de Lingüística Indígena 9

Nercesian, V. (2008). La negación en wichí. En Messineo C., M. Malvestitti y R. Bein (eds.), Estudios en lingüística y antropología. Homenaje a Ana Gerzenstein (pp. 167179). Buenos Aires: Universidad de Buenos Aires.

Nercesian, V. (2009/2010). Construcciones de verbos seriales en wichí (mataguaya). Características sintácticas y semánticas. Amerindia, 33-34, 187-216.

Nercesian, V. (2011). Gramática del wichí, una lengua chaqueña. Interacción fonología-morfología-sintaxis en el léxico (Tomos 1 y 2). Tesis doctoral. Universidad de Buenos Aires. Publicada en: http://repositorio.filo.uba.ar/ handle/filodigital/1466.

Nercesian, V. (2013). Bases lingüísticas y sociohistóricas del estudio dialectal del wichí/weenhayek. (Ponencia presentada en el VII Bolivian Studies Association International Congress/2013. Sucre, 29 de julio-1 de agosto de 2013).

Nercesian, V. (2014). Wichi Ihomtes. Estudio de la gramática y la interacción fonología-morfología-sintaxissemántica. Múnich: LINCOM.

Nercesian, V. (2019a). Variación dialectal y diacrónica del objeto pronominal en wichí/weenhayek (mataguaya): paradigmas prefijante y sufijante. Cuadernos de Lingüística de El Colegio de México, 6(1), e127.

Nercesian, V. (2019b). Rasgos fonológicos y gramaticales de variación dialectal en wichi/weenhayek (mataguaya). (Ponencia presentada en el III Congreso de la Delegación Argentina de la Asociación de Lingüística y Filología de América Latina. Universidad Nacional de La Plata, Ensenada, 24-27 de abril).

Nercesian, V. (En prensa) Isoglosas fonológicas wichi/ weenhayek (mataguaya): consonantes eyectivas, glotalizadas y aspiradas. Lingüística, 37, junio 2021.

ORCAWETA [Organización Capitanía Weenhayek y Tapiete]. 2011. "Resultados del censo Weenhayek". En Plan Estratégico de desarrollo del pueblo weenhayek 2011-2015. Tarija, Bolivia.

Pelleschi, J. (1897). Los indios matacos y su lengua, con una introducción por S. A. Lafone Quevedo M. A. y dos mapas. Buenos Aires: La Buenos Aires.

Remedi, J. (1896). Los indios matacos y su lengua. Con vocabulario ordenado por Lafone Quevedo. Boletín del Instituto Geográfico Argentino. Tirada Aparte. Buenos Aires: Instituto Geográfico Argentino.

Seelwische, J. y Stell. N. (2015). Nivaclé dictionary. En Key, M.R. y Comrie, B. (Eds.), The Intercontinental Dictionary Series. Leipzig: Max Planck Institute for Evolutionary Anthropology. http://ids.clld.org/contributions/307

Serrudo, A. E. 2006. Interculturalidad y práctica escolar: el maestro auxiliar bilingüe en la experiencia de la Escuela N4266 «Río Bermejo». Carboncito, provincia de Salta. Tesis de Licenciatura, Universidad Nacional de Salta.

Susnik, B. (1972). Dimensiones migratorias y pautas culturales de los pueblos del Gran Chaco y de su periferia. Enfoque etnológico. Corrientes. Universidad Nacional del Nordeste.

Stell, N. (1987). Gramática descriptiva de la lengua nivacle (chulupí). Tesis doctoral. Universidad de Buenos Aires.

Tacconi, T. (2015). Formación de palabras en maká 
(mataguayo). Tesis doctoral. Universidad de Buenos Aires.

Terraza, J. (2009a). Grammaire du Wichi: Phonologie et Morphosyntaxe. Tesis Doctoral, Universidad de Québec.

Terraza, J. (2009b). El repertorio fonológico del wichí de Rivadavia. En Fernández Garay, A. y M. Censabella (comps.), Estudios fonológicos de continua dialectales mapuche y wichí (pp. 41-82). La Pampa: Universidad Nacional de La Pampa.

Tovar, A. (1951). Un capítulo de lingüística general. Los prefijos posesivos en lenguas del Chaco y la lucha entre préstamos morfológicos en un espacio dado. Boletín de la Academia Argentina de Letras, 20, 360-403.

Tovar, A. (1958). Notas de campo sobre el idioma mataco, Separata de la Revista del Instituto de Antropología 9(2), 7-18.

Tovar, A. (1961). Catálogo de lenguas de América del Sur. Buenos Aires: Sudamericana.

Tovar, A. (1964). El grupo mataco y su relación con otras lenguas de América del Sur. Actas del $35^{a}$ Congreso internacional de americanistas II, 439-452.

Tovar, A. (1981). Relatos y diálogos de los matacos. Madrid: Ediciones Cultura Hispánica.

Trudgill, P. (2011). Sociolinguistic Typology. Social Determinants of Linguistic Complexity. Oxford: Oxford University Press.
Vidal, A. y Braunstein, J. (2020). The Southern Plains and the Continental Tip. En Güldemann, T., McConvell, P. y Rhodes, R.A. (Eds.). The Language of HunterGatherers (pp. 641-669). Cambridge: Cambridge University Press.

Viegas Barros, P. (1993). ¿Existe una relación genética entre las lenguas mataguayas y Guaycurúes? En Braunstein, J. (Ed.). Hacia una nueva carta étnica del Gran Chaco, 4, 193-213.

Viegas Barros, P. (2002). Fonología del ProtoMataguayo: Las fricativas dorsales. En Crevels, M., van de Kerke, S., Meira, S. y van der Voort, H. (Eds.), Current Studies on South American Languages [Indigenous Languages of Latin America, 3] (pp. 137-148). Leiden, Research School of Asian, African, and Amerindian Studies (CNWS).

Viegas Barros, P. (2013). La hipótesis de parentesco guaicurú-mataguayo (Gran Chaco). Estado actual de la cuestión. Revista Brasileira de Lingüística Antropológica, 5(2), 293-333.

Viñas Urquiza, M. T. (1970). Fonología de la lengua Mataca. Buenos Aires: Universidad de Buenos Aires.

Viñas Urquiza, M. T. (1974). Lengua mataca, 2 tomos. Buenos Aires: Facultad de Filosofía y Letras, UBA.

Wichmann, S. y Holman, E.W. (2009). Assessing temporal stability for linguistic typological features. Múnich: LINCOM Europa. 
Anexo. Lugar de origen de los datos analizados, trabajos de campo (TC) y fuentes consultadas.

\begin{tabular}{|c|c|c|c|}
\hline \multirow{3}{*}{$\begin{array}{l}\text { Estado } \\
\text { Plurinacional de } \\
\text { Bolivia }\end{array}$} & \multirow[t]{3}{*}{ Tarija } & \multirow[t]{2}{*}{ comunidades del río Pilcomayo } & Claesson (1994) \\
\hline & & & $\begin{array}{l}\text { Alvarsson } \\
1984)\end{array}$ \\
\hline & & $\begin{array}{l}\text { Tuuntey, Capirendita, Tsimukat km1 (Villamontes), } \\
\text { Las Tres Moras (Crevaux) }\end{array}$ & Nercesian, TC \\
\hline \multirow[t]{12}{*}{ Argentina } & \multirow{6}{*}{ Salta } & Misión La Paz & Avram (2008) \\
\hline & & $\begin{array}{l}\text { Embarcación, San Andrés/Misión La Paz, migrante } \\
\text { de Embarcación en Tartagal }\end{array}$ & Tovar $(1958,1981)$ \\
\hline & & $\begin{array}{l}\text { Lapacho Mocho (Tartagal), Misión Santa María, } \\
\text { Santa Victoria Este, Las Vertientes, Paraje La Paz } \\
\text { (Coronel Juan Solá) }\end{array}$ & $\begin{array}{l}\text { Fernández Garay y } \\
\text { Spinelli (2009) }\end{array}$ \\
\hline & & Lapacho II (Tartagal), Alto la Sierra, La Junta & Nercesian, TC \\
\hline & & Misión Chaqueña, Tartagal & $\begin{array}{l}\text { Viñas Urquiza } \\
(1970,1974)\end{array}$ \\
\hline & & Bo. La Misión (Rivadavia) & $\begin{array}{ll}\text { Terraza } & (2009 a, \\
2009 b)\end{array}$ \\
\hline & \multirow[t]{5}{*}{ Formosa } & comunidades del río Pilcomayo (Ramón Lista) & Lunt (1999) \\
\hline & & $\begin{array}{l}\text { Bo. Nuevo, El Potrillo, San Martín, Quebracho, Lote } \\
\text { 8, Las Cañitas, Pozo Caballo, María Cristina, El } \\
\text { Silencio, Villa Devoto, San Miguel, El Chorro, Pozo } \\
\text { Cercado, Tucumancito, Campo del Hacha, Tres } \\
\text { Palmas, Tronquito (Ramón Lista) }\end{array}$ & DIRLI (2003) \\
\hline & & María Cristina & Nercesian, TC \\
\hline & & $\begin{array}{l}\text { Bo. Obrero y Bo. Viejo (Ing. Juárez), Bo. La Unión, } \\
\text { Cacique Yemu, Wichi Lawet y Matadero (Laguna } \\
\text { Yema), Tich'a (Pozo del Mortero), Tres Pozos } \\
\text { (J.G.Bazán), La Pantalla, Lote } 27 \text { y Colonia Muñiz } \\
\text { (Las Lomitas), Lakawichi (Pozo del Tigre) }\end{array}$ & $\begin{array}{l}\text { Nercesian (2011, } \\
\text { 2014) }\end{array}$ \\
\hline & & Colonia Muñiz (Las Lomitas) & $\begin{array}{l}\text { Gerzenstein } \\
(1991 / 1992,2003)\end{array}$ \\
\hline & Chaco & Sauzalito, Nueva Pompeya, Pozo del Sapo & $\begin{array}{l}\text { Nercesian (2011, } \\
\text { 2014) }\end{array}$ \\
\hline
\end{tabular}

